\title{
Regimes, management and economics of energy complexes on the basis of renewable energy sources for autonomous power supply
}

\author{
$V$. Elistratov ${ }^{1, *}$, and $I$. Kudryasheva $^{1}$ \\ ${ }^{1}$ Peter the Great St. Petersburg Polytechnic University, St. Petersburg, Russia
}

\begin{abstract}
The article describes the principles of creation, management and economics of power complexes based on renewable energy sources for decentralized power supply. The introduction of energy complexes based on renewable energy sources can compete with the centralized power supply of the regions by increasing energy security and reducing the risks of major accidents and disasters. Long-term contracts for the electricity supply can be a reliable and economical insurance in case of rising fuel prices in the long term.
\end{abstract}

\section{Background}

The introduction of renewable energy technologies means a transition from a model of concentrated centralized energy development to a model of deconcentrated energy with the impossibility of major accidents and disasters. Strategic priorities for the development of generation based on renewable energy will ensure the energy and environmental safety of the Russian regions.

Most of the Russian territory of is not connected to centralized energy systems and receives electricity, mainly from autonomous diesel generators of small capacity. The generated energy in these cases turns out to be very expensive, since the main component of the delivery depending on weather conditions and carried out by road, waterways or helicopters. The use of local renewable energy resources (RES) enables to increase the efficiency of the decentralized energy supply and the region's coefficient of self-sufficiency in the fuel and energy resources [1].

Renewable energy resources are becoming more competitive in many countries. In a number of markets with sufficient resources, the normalized cost of energy generated by land-based wind farms may compete with new coal-based and natural gas power plants. Long-term electricity supply contracts can be an effective and economical insurance in the event of a rise in fuel prices in the long term, even in the absence of tax incentives at the federal level.

Competition of renewable energy sources depends on the market and economic policy: an increase in the power plants' capacity and the volume of renewable energy facilities' financing leads to a reduction in the cost of electricity and more efficient use of natural resources.

\section{Purpose}

Optimization and modernization of the existing energy supply systems of the arctic territories can be carried out on the basis of the creation of energy complexes (EC) using renewable energy sources, for instance, winddiesel power plants (WDPP) with a high proportion of diesel fuel substitution. Such energy complexes should be adapted to the harsh northern conditions: low temperatures down to $-50^{\circ} \mathrm{C}$, frost, permafrost soils and other extreme conditions [2].

The world implementation experience, management and operation of $\mathrm{EC}$ in regions with an arctic and subarctic climate cannot be fully transferred to Russian conditions. This is due to the more severe natural and climatic characteristics of the Russian North, limited transport and construction infrastructure, as well as the market's offers for the average power wind turbines (up to $100-150 \mathrm{~kW}$ ) according to the operation specifics, the lack of domestic equipment, software products and EC's control systems with a high-level renewable energy equipment substitution [3].

\section{Methods}

In order to create an efficient and competitive autonomous power supply system based on renewable energy sources adapted to northern conditions, Peter the Great St. Petersburg Polytechnic University developed a methodology for calculating the optimal parameters and operating modes of an autonomous $\mathrm{EC}$ with a domestic smart power conversion, control and distribution system to ensure reliable and efficient power supply to remote consumers in harsh climatic conditions [4].

\footnotetext{
* Corresponding author: elistratov@ spbstu.ru
} 
The establish of such an autonomous power supply system with a smart control will enable the fullest possible use of wind energy resources (of which $30 \%$ of the technical potential is concentrated in the northern regions), apply unified equipment adapted to the Russian Arctic conditions, increase the reliability and environmental safety of the territories' power supply, take into account systemic effects and attractiveness of potential investors when creating hybrid EC.

The smart control system of autonomous wind-diesel EC (WDEC) [5] in real time, based on information on the state, parameters and resources of RES for the current and past time periods, allows you to control the modes of WDEC operation. The software and hardware module of the smart power conversion, control and distribution system provides the possibility of maximizing the energy production from renewable energy sources due to the dynamic redistribution of power between the elements of the energy complex and minimizing fuel consumption.

Generalizing condition of dynamic power redistribution in an autonomous EC is the performance of the power balance: the power of the consumed energy must be equal to the power of the generated energy. Power balance provides stabilization of the frequency and voltage of the autonomous network.

The market price of electricity largely depends on the price of fuel, i.e. while dominance in the market of fossil fuel power plants (they currently produce more than $50 \%$ of all electricity consumed by $15 \mathrm{EU}$ countries). The cost of electricity from systems for renewable energy is calculated using efficiency criteria that take into account the change in the value of money over time, the interest rate for borrowed funds and the risk premium depending on the scale of the project.

The economy of decentralized generation depends on a number of factors and, above all, on initial investment, the cost of diesel fuel, electricity tariffs, the cost of connecting to the network. The development of energy systems based on renewable energy is, to a certain extent, determined by the system of legislative measures and incentive measures taken both within the European Union and in individual countries [6-8].

The choice of WDEC scheme with an appropriate substitution level is determined by a number of factors: natural and climatic conditions, the presence of a certain infrastructure, financial possibilities, the amount of generation required, the required quality of electricity [9].

The EC control system is shown in figure 1.

Principles of creating effective EC in autonomous generation [10]:

- reliable assessment of wind resources at the EC's location in conditions of limited information;

- optimization of the EC's parameters and modes of operation based on the complex criteria;

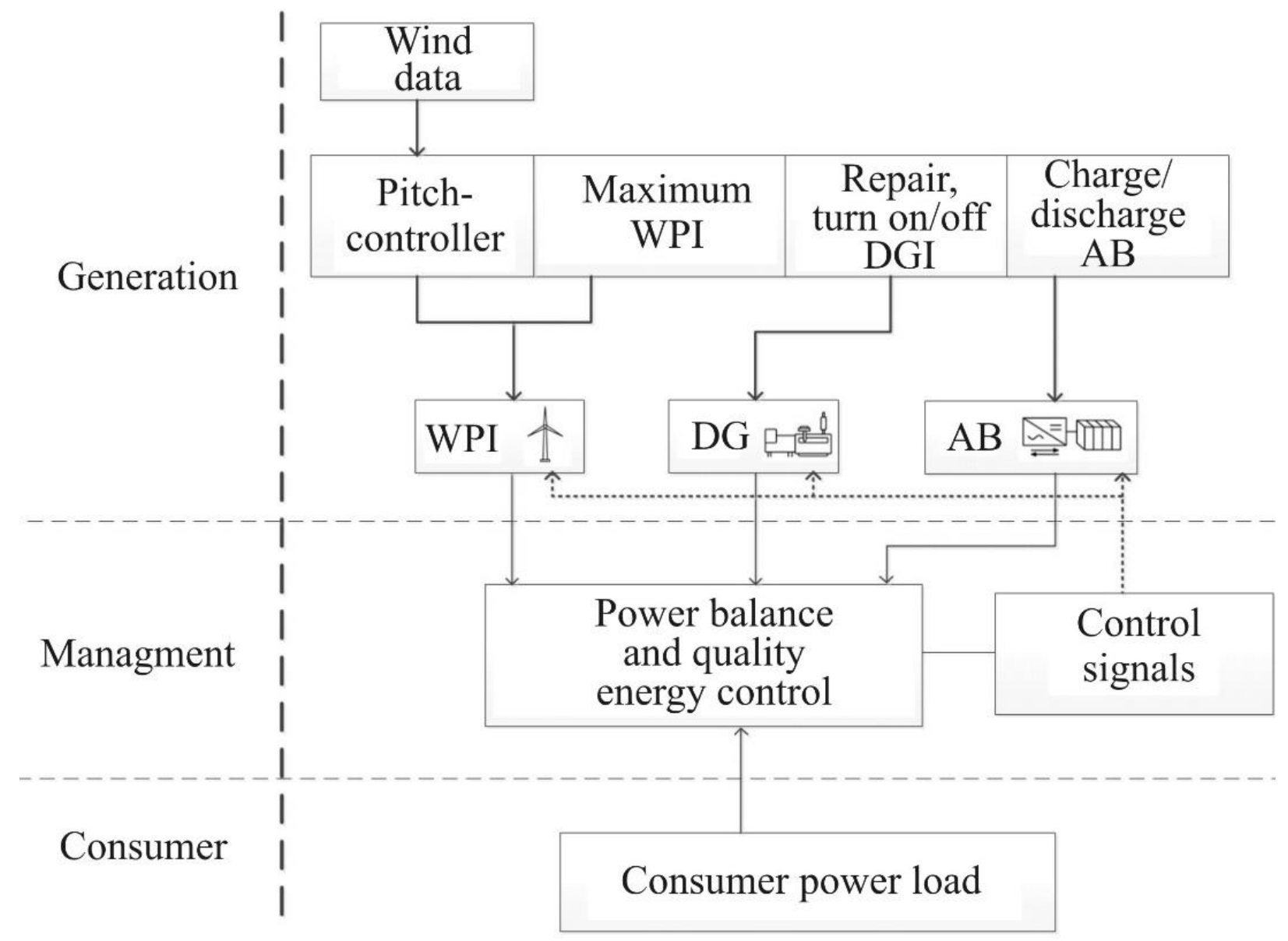

Fig. 1. Control system of energy complex. 
- applying an automatic control system that provides a high level of diesel fuel substitution;

- applying of equipment specially designed and adapted to the arctic conditions;

- justification of investments in EC based on systemic efficiency.

To select the optimal scheme of the main and auxiliary equipment, the Homer software package can be used. The modeling process in Homer software package is based on the calculation of the energy balance at each point in time. Therefore, the calculation of the generated and consumed energy is carried out with the subsequent redistribution of the generated energy for consumer needs and the charge of the accumulating batteries or ensuring the heat load. Such calculations are performed for each system configuration, after which the economic component of the project options is estimated - capital investment, equipment replacement cost, operation and maintenance costs, fuel price, etc [11].

To simulate the variants of the wind-diesel power complex implementation, the following initial data were used: consumer hourly load during the year, average daily load profiles for each month; a series of hourly observations of the wind speed of the satellite surveillance system MERRA, obtained by exporting from WindPro software package and scaled for the selected construction site of WDEC [12].
Modelling of wind-diesel power complex variants is carried out by successive addition of one wind turbine to the diesel generator (DG) scheme in the amount from 1 to 10 units (figure 2). The composition of the equipment of a diesel power plant, which is part of the power complex, is the same in each design variant and corresponds to the initially functioning scheme.

In the composition of the options with a high proportion of replacement, there are voltage converters and batteries. The installed capacity of the converters is assumed to be $30 \%$ of the installed capacity of WPP. The number of batteries is determined by calculations in the Homer software package [13].

In the selected WDEC scheme with a high level of replacement, the excess electricity is $12.1-25.3 \%$ with one and up to ten wind turbines, smart control system, a secondary load control controller and a ballast load are required. Using the battery for partial accumulation of the generated electricity will reduce the number of DG hour operation and reduce fuel consumption for them. In addition, the battery is necessary for the operation of the voltage converter, whose work is interconnected with the wind turbine inverter operation [14].

The main criteria for each type of equipment evaluation are the following indicators: power generation for each type of equipment; the number of the generating equipment hour operation; amount of fuel consumed;

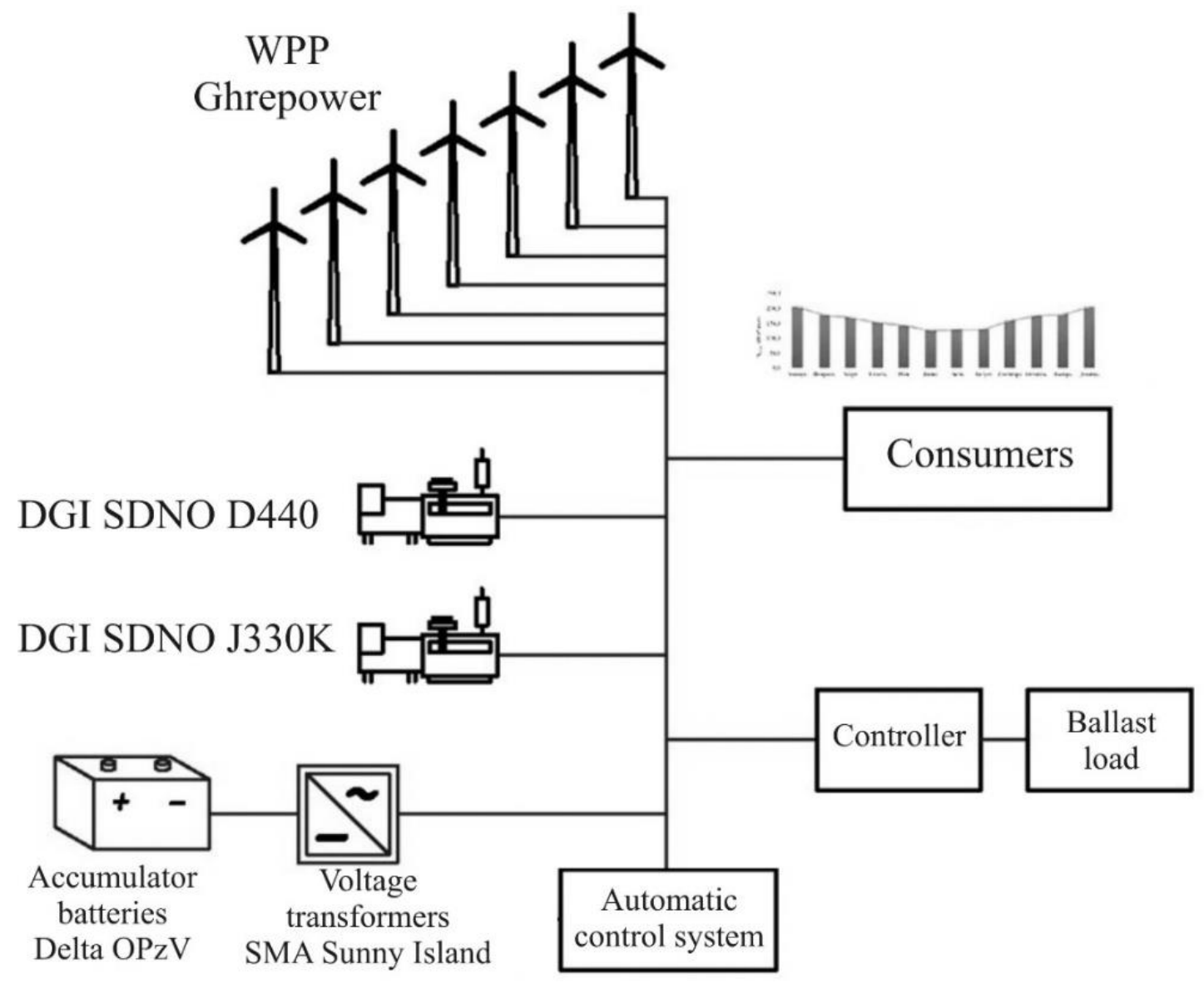

Fig. 2. WDEC structure scheme. 
total discounted project costs; share of renewable generation.

The solution of the system problem of assessing the economic efficiency of projects based on renewable energy sources It is found in the solution of the general problem of optimizing the parameters and modes of operation of EC based on renewable energy [15].

The assessment technigue (figure 3) integrates information obtained from the modules for assessing the resource potential and the module for justifying the equipment parameters and, using regional databases of tariff regulation, fuel prices, financial and economic indicators, allows for the calculation of economic indicators of the project taking into account financing schemes discount rates and risk components.

\section{Results}

Our studies on the assessment of economic efficiency in Tiksi (Sakha-Yakutia) [16] showed that the developed method allows the selection of the most optimal option for implementing a decentralized generation project for renewable energy and reduces the cost of electricity production, reducing regional subsidies, increasing the investment attractiveness of the project, reducing costs diesel fuel and reducing its volume, reducing $\mathrm{CO}_{2}$ emissions.

\section{Conclusions}

1. Prospects for the development of projects of decentralized energy supply based on renewable energy sources will provide a significant environmental impact through energy production in renewable energy installations.

2. The development of energy conversion technologies for renewable energy is innovative in nature, providing increased efficiency and reduced material consumption and the cost of electricity production.

3. RES-based power supply systems provide reliable power supply and power quality

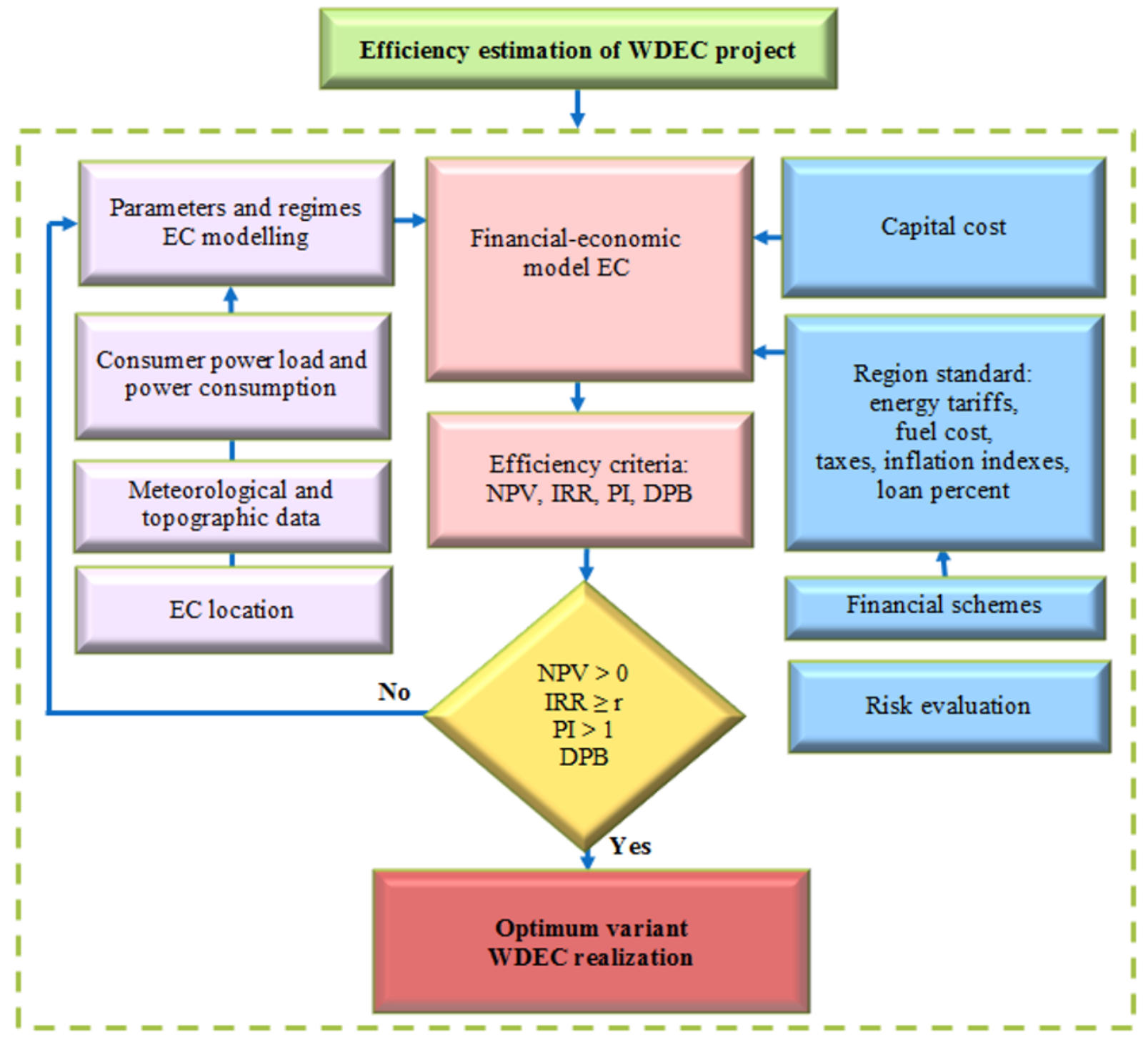

Fig. 3. Block-diagram of technique for optimum parameters and operating modes of an autonomic power complex. 


\section{References}

[1] V. Elistratov, Renewable energy (St. Petersburg: Science) (2016)

[2] V. Elistratov, and I. Kudryasheva, ARPN Journal of Engineering and Applied Sciences Methodology for parameters selection and evaluation the effectiveness of decentralized energy supply systems based on renewable energy sources 11(5), 3509-12 (2016)

[3] V. Elistratov, M. Konischev, and $\mathrm{M}$. Fedorov, Int. Conf. on Industrial Engineering, Applications and Manufacturing Optimization of power supply of the circumpolar territories on the basis of renewable energy sources $\mathbf{8 0 7 6 2 2 0}$, (2017)

[4] V. Elistratov, and M. Konishev, Int. Journal "Alternative energy and ecology" Wind-diesel power plants for autonomous power supply of the northern territories of Russia 11(151), 62-70 (2014)

[5] V. Elistratov, R. Denisov, M. Konishev, and M. Knyazhevich, Journal of Applied Engineering Science Problem of constracting wind-diesel power plants in harsh climatic conditions 12(1), 29-36 (2014)

[6] http://leonardo-energy.org

[7] O.A. Jaramillo, M.A. Borja, and J.M. Huacuz, Renewable Energy Using hydropower to complement wind energy: a hybrid system to provide firm power 29, 1887-1909 (2004)

[8] C.P. Daniel, Prowse Wind Energy International Combining wind and hydropower 365-70 (2011)

[9] R. Hunter, and G. Elliot, Wind-Diesel Systems: A Guide to the Technology and its Implementation (University of Cambridge) (1994)

[10] V. Elistratov, and I. Kudryasheva, Int. Ural Conf. on Green Energy, UralCon Methodology of WindDiesel Power Complexes Parameters Justification for Decentralized Supply of Arctic Regions 8544298, 12732 (2018)

[11] P. Pilipec, and I. Kudryasheva, 3th National scientific research Conf. Hydropower plants in XXI century Research of energy complexes operation regimes on the base of traditional and renewable energy sources 251-5 (2016)

[12] T.L. Acker, A. Robitaille, H. Holttinen, M. Piekutowski and J. Olav, Giver Tande Wind Engineering Integration of Wind and Hydropower Systems: Results of IEA Wind Task 24, 1-18 (2012)

[13] D.K. Lal, B.B. Dash and A.K. Akella, International Journal on Electrical Engineering and Informatics Optimization of PV/Wind/MicroHydro/Diesel Hybrid Power System in HOMER for the Study Area 3, 307-25 (2011)

[14] V. Elistratov, and R. Denisov, Int. Conf. on Industrial Engineering, Applications and Manufacturing, ICIEAM Justification of wind turbine operation and management modes for Russian arctic conditions 8076219, (2017)

[15] C. George, Bakos Applied Energy Feasibility study of a hybrid wind/hydro power-system for low-cost electricity production 72, 599-608 (2002)
[16] V. Elistratov, I. Kudryasheva, and P. Pilipets, Applied Mechanics and Materials Energy efficient solutions of power supply in north regions $\mathbf{7 2 5 - 7 2 6}$, 1463-70 (2015) 